\title{
Impactos socioambientais causados pela prática de Motocross no município de São Francisco de Paula/RS
}

\author{
Rochele Altmayer de Souza ${ }^{1}$ e Patrícia Binkowski ${ }^{*}$
}

${ }^{1}$ Universidade Estadual do Rio Grande do Sul, Rua Assis Brasil, 842 - Centro, CEP: 95400-000. São Francisco de Paula, RS. E-mail: rochelealtmayer@gmail.com

2 Universidade Estadual do Rio Grande do Sul, Rua Assis Brasil, 842 - Centro, CEP: 95400-000. São Francisco de Paula, RS.

E-mail: patricia-binkowski@uergs.edu.br

* Grupo de Pesquisa Observatório dos Campos de Cima da Serra/RS (ObservaCampos). Universidade Estadual do Rio Grand do Sul - São Francisco de Paula, RS, Brasil.

ISSN 2448-0479

Resumo - Este artigo é fruto do Trabalho de Conclusão de Curso (TCC) do Curso de Graduação do Bacharelado em Gestão Ambiental da Unidade Universitária em São Francisco de Paula, da Universidade Estadual do Rio Grande do Sul (UERGS). O objetivo geral do TCC foi o de identificar os principais impactos socioambientais causados pela prática de motocross no município de São Francisco de Paula, Rio Grande do Sul e, analisar a percepção dos atores sociais envolvidos no conflito. Para a realização deste trabalho, foram realizadas visitas nos locais de ocorrência do motocross, entrevistas, utilização de diário de campo, sistematização de dados e revisão bibliográfica. A pesquisa constatou que ocorrem impactos socioambientais negativos nos locais e no entorno de onde sáo realizadas as trilhas de motocross no município como, por exemplo, vazamento de combustíveis nos recursos hídricos, compactação e erosão do solo, afugentamento da fauna local, abertura irregular de trilhas, aparecimento de sulcos no solo e invasões irregulares em propriedades particulares.

Palavras-chave - Impactos socioambientais. Motocross. Trilhas. São Francisco de Paula.

Abstract - This article is the fruit of Work of conclusion of course (CBT) of the Bachelor degree course in environmental management of the University Unit in San Francisco de Paula, the State University of Rio Grande do Sul (UERGS). The overall objective of the project was to identify the main environmental impacts caused by the practice of motocross in the municipality of San Francisco de Paula, Rio Grande do Sul, and analyze the perception of social actors involved in the conflict. For this study, were carried out visits in places of occurrence of the motocross, interviews, use of field journal, data systematization and bibliographical review. The research found that social and environmental negative impacts occur in the places and surroundings where motocross trails are held in the municipality, such as fuel leak in water resources, soil erosion, compaction and the resulting disappearance of local fauna, irregular opening of trails, appearance of grooves in the soil and irregular invasions on private properties.

Keywords - Social and Environmental Impacts. Motocross. Trails. São Francisco de Paula.

Recebido em: 27 de agosto de 2016

Aprovado em: 16 de setembro de 2016

\section{INTRODUÇÃO}

As mudanças ocorridas no meio ambiente acompanham a evolução do ser humano enquanto ser social. Essas mudanças ocorrem no uso de novos meios, novas tecnologias e novas técnicas, sejam elas referentes à produção econômica, sejam referentes a mecanismos para a melhoria do bem estar social. Entretanto, algumas dessas mudanças sócio-técnicas vêm provocando 
efeitos negativos para a sociedade. É o que constata Marques (2009, p.20) quando comenta que a:

sociedade contemporânea está sob constante e rápida transformação e, de forma geral, o motor tem sido o progresso técnico e o crescimento econômico, rumando, aparentemente, para uma homogeneização material e cultural.

Tal transformação não se dá apenas no âmbito social, mas também em nível ambiental cujo processo de degradaçấo da biodiversidade atinge diversas partes do mundo. A origem deste processo e sua significação para a sociedade tornaram-se evidentes nos últimos 30 anos (ZANONI, 2004), ficando claro que a intervenção humana, o crescimento populacional, as práticas inadequadas na agropecuária, as construçóes de complexos industriais (BALSAN, 2006) contribuíram para um cenário ambiental totalmente desordenado.

Em função dos altos índices de degradação ambiental causados em meados dos anos 1970 e na década de 1980, principalmente, pelo modelo de desenvolvimento predatório é que a temática ambiental tornou-se objeto de ampla reflexão nas últimas décadas, pautando discussóes, delimitando e consolidando uma sólida presença, em especial nos debates acadêmicos (BACCHIEGGA, 2012).

A questão ambiental é um dos focos do curso de Bacharelado em Gestáo Ambiental da UERGS na Unidade Universitária em São Francisco de Paula, cujos docentes dos componentes curriculares tem buscado problematizar sobre os impactos socioambientais tendo a região dos Campos de Cima da Serra como exemplo. E é em São Francisco de Paula, por exemplo, que se apresenta um tema bastante polêmico em relação à possível geração de impactos socioambientais causados por esportes de aventura (motocross ${ }^{1}$, montain bike, rapel, trekking, off-road entre outros). As características naturais do município influenciam diretamente na prática desse tipo de esporte, por apresentar privilegiada geografia, relevo, mata subtropical fechada, rios e áreas de altitudes propícias.

Segundo Santana (2011) a utilização de algumas áreas pelos esportistas de aventura vem causando impactos ambientais e descaracterizaçóes socioculturais, sendo necessárias medidas de manejo e de gestão ca-

\footnotetext{
${ }^{1}$ Optou-se em preservar o termo estrangeiro motocross por ser utilizado entre os participantes que foram entrevistados nesta pesquisa, por isso também, o termo está em itálico.
}

pazes de minimizar tais impactos negativos e de analisar futuras atividades. As preocupaçóes também têm sido direcionadas às atitudes dos praticantes dessas modalidades, buscando caminhos que possibilitem práticas mais conscientes e sustentáveis.

Apesar de serem atividades de esporte/aventura, muitas vezes são tidas ou divulgadas como "ecológicas”, por vezes, pela simples falta de informação sobre o esporte e/ou mesmo pela falta de consciência ambiental. Geralmente, o que se tem observado é que os praticantes deste tipo de esporte não estão levando em consideração medidas que visem minimizar os possíveis impactos que podem decorrer de suas práticas. Em muitos casos fica comprovado que a natureza nada mais representa que um ambiente cheio de obstáculos a serem vencidos ou superados.

O motocross (ou Moto X ou MX) é uma dessas modalidades que são realizadas em São Francisco de Paula, constatando-se que nos últimos 5 anos houve uma grande quantidade de adeptos. $\mathrm{O}$ motocross foi criado na Inglaterra no início do século XX e é definido como uma corrida de alta velocidade sobre duas rodas em circuitos de terra fora de estrada (PAIXÃO; NAZARI, 2010). É um esporte de motovelocidade praticada sobre motocicletas de estilo Off-Road ${ }^{2}$. Este esporte seria uma corrida com vários modelos e tipos de motos, dividindo-se em várias categorias, como: arenacross, trial e enduro.

Sabe-se que para o desenvolvimento do motocross, a natureza é essencial, uma vez que o esporte explora os recursos naturais, como córregos, trilhas, matas, morros, entre outros. No entanto, a prática de motocross em São Francisco de Paula não tem se comprometido com a sustentabilidade do ambiente e tem provocado impactos socioambientais pelas trilhas onde passam, originado inúmeros conflitos entre os praticantes do motocross e os moradores locais, como será comentado nas próximas seções.

\section{REFERENCIAL TEÓRICO E METODOLÓGICO}

\subsection{Impacto (Socio)Ambiental}

Segundo a Normatização Brasileira - ISO 14001 (ASSOCIAÇÃO BRASILEIRA DE NORMAS TÉCNICAS, 2004), o impacto ambiental é qualquer

\footnotetext{
2 O Off Road chegou no Brasil na década de 1980, quando começaram a aparecer os primeiros rallys. Atualmente, nesta modalidade existem motocicletas, automóveis, caminhốes e quadrículos, divididos em várias categorias (AMORIM et. al., 2005).
} 
modificação do meio ambiente, adversa ou benéfica, que resulte no todo ou em parte, das atividades, produtos ou serviços de uma organização. Para o Conselho Nacional do Meio Ambiente (CONAMA), impacto ambiental é "qualquer alteração das propriedades físicas, químicas e biológicas, causada por qualquer forma de matéria ou energia resultante das atividades humanas que, direta ou indiretamente" (CONSELHO NACIONAL DO MEIO AMBIENTE, 2008).

Prado (2013) comenta que a ideia de "impacto ambiental" como é entendida hoje, surgiu há mais de três décadas, nos primeiros anos do estabelecimento de um ordenamento jurídico ambiental no Brasil. O autor comenta que a noçâo hoje consolidada de "impacto ambiental" surgiu na legislação ambiental brasileira em 1986. Conforme Prado (2013), a Resolução 001/86 do CONAMA instituiu a categoria "impacto ambiental" e esse conceito irá consolidar-se por meio dos estudos e relatórios a partir daí exigidos como o Estudo de Impacto Ambiental (EIA), o Relatório de Impacto de Meio Ambiente (RIMA) e o Estudo de Impacto de Vizinhança (EIV).

Essas ferramentas de análise ambiental - EIA, RIMA e EIV -, foram colocadas em prática em função dos licenciamentos ambientais, sendo elas as que mais se utilizam da categoria analítica de "impacto ambiental” (PRADO, 2013). Já para Torres (2006), a ideia de "impacto ambiental" constitui-se como um pilar central do ordenamento jurídico ambiental brasileiro, mesmo que tenham surgido outras ferramentas de avaliação, estas não tiveram a mesma força.

Impacto ambiental para Philippi Jr. e Maglio (2005) enfoca a transformação ou alteração de qualquer forma do meio ambiente, seja ele físico, ecológico ou social, com o intuito de preservar a qualidade ambiental. Segundo estes autores "a qualidade do ambiente refere-se ao resultado dos processos dinâmicos e interativos dos componentes do sistema ambiental, que compreendem seus componentes físicos, bióticos, sociais e econômicos" (PHILIPPI JÚNIOR; MAGLIO, 2005, p. 232).

A partir da década de 1980 os processos de degradação dos ambientes passaram a considerar também o viés social na produção do espaço (FERNANDES, 2004). Deste modo, a noção a ser utilizada neste trabalho é a de impactos socioambientais, contemplando a dimensão social da degradação ambiental. O termo "socioambiental" enfatiza o necessário envolvimento da sociedade enquanto parte fundamental dos pro- cessos relativos à problemática ambiental contemporânea (MENDONÇA, 2002). Assim, o espaço natural e a problemática social devem ser analisados conjuntamente, para um entendimento metodologicamente mais aprofundado a respeito das dimensóes de desigualdade que ameaçam as sociedades e a integridade dos ecossistemas (FERREIRA, 2011).

Portanto, estaria a prática de motocross causando impactos socioambientais no município de São Francisco de Paula? Para Santana (2011), os maiores impactos decorrentes deste tipo de esporte são: a) impactos à paisagem pela abertura e utilização de trilhas, inclusive em Áreas de Proteção Ambiental (APA); b) erosão e compactaçâo do solo; c) assoreamento de córregos e nascentes; d) alteração e destruição da vegetaçấo e de habitat de animais; e) poluiçáo: barulho, lixo, emissão de gases e petróleo (combustível); f) interferências social e cultural em comunidades próximas envolvidas. Em outro estudo, Moraes (2014) comprova que a prática de motocross provoca impactos como: emissão de ruídos, interferência no trânsito local, geração de resíduos, uso e ocupação do solo, perturbaçáo a fauna e mudança na rotina de vida da comunidade local de onde ocorrem os eventos de motociclismo.

Os impactos se tornam ainda maiores com o aumento do número de motocicletas nas trilhas, especialmente em períodos chuvosos. Santana (2011) comenta que os prejuízos decorrentes da falta de planejamento desta atividade podem afetar, além dos recursos naturais, setores importantes da economia local, como é o caso do turismo.

Salvati (2001) afirma que a fragilidade dos ecossistemas naturais, muitas vezes, não comporta repetidos enduros. Por outro lado, a infraestrutura necessária, se não atendida às normas pré-estabelecidas, pode comprometer imensamente o meio ambiente, com alterações na paisagem, na topografia, no sistema hídrico e na conservação dos recursos naturais florísticos e faunísticos.

Costa (2004), confirma que pesquisas sobre os impactos negativos em áreas protegidas estão sendo desenvolvidas comparando os impactos provocados pelos caminhantes, pelo uso de cavalos, pelas motocicletas ou motocross e por mountain bike. Algumas dessas pesquisas têm apontado os impactos sociais como os mais perceptíveis devido à relação com a experiência do uso dos visitantes, principalmente, o conflito existente entre os diversos usuários e os diferentes usos das trilhas (COSTA, 2004). 


\subsection{Procedimentos metodológicos}

A presente pesquisa foi elaborada seguindo uma abordagem mista (confluência do método qualitativo e quantitativo), partindo de um estudo exploratório, descritivo e interpretativo sobre os impactos socioambientais do motocross em São Francisco de Paula/RS.

Gil (2008) afirma que a ciência tem como objetivo fundamental chegar à veracidade dos fatos. O que torna o conhecimento científico distinto dos demais é que ele apresenta uma característica fundamental, a sua verificabilidade.

Hoje, os cientistas e os filósofos da ciência entendem haver uma diversidade de métodos, que são determinados pelo tipo de objeto a investigar e pela classe de proposiçôes a descobrir. Conforme Gil (2008), estes métodos esclarecem quais os procedimentos lógicos que deverão ser seguidos no processo de investigação científica dos fatos da natureza e da sociedade.

Na década de 1950 houve uma ligeira decadência do método qualitativo, tido pelos positivistas como sendo "metodologia fora de padráo" (BOGDAN; TAYLOR, 1975 apud SILVA, 1996). Silva (1996) comenta que o que antes era visto como não científico, hoje se admite como procedimento mais adequado ao estudo de determinados tipos de fenômenos ligados ao ser humano e sua vida em sociedade.

A primeira etapa da pesquisa se deu por meio de revisão bibliográfica em fontes secundárias (metadados) textos, artigos, estatísticas, documentos, legislação.

De acordo com Trivińos (1990) a "análise documental" é outro tipo de estudo descritivo que fornece ao investigador a possibilidade de reunir uma grande quantidade de informaçốes sobre as leis, processos, condiçóes, planos etc. Nesta pesquisa, a análise documental se deu a partir do catálogo dos seguintes documentos oficiais: a) Documento 1 - Plano Ambiental Municipal de São Francisco de Paula (2008); b) Documento 2 - Resolução no 357 de 17 de março de 2005, Capítulo II - Da Classificaçáo dos Corpos de Água - Seçấo I - Das Águas Doces; c) Documento 3 Resolução no 5, de 15 de junho de 1989. Correlaçóes: Complementada pelas Resoluçóes CONAMA no 3 e 8/90; d) Documento 4 - Resoluçáo no 18 , de 6 de maio de 1986 - VI - Estabelecer os limites máximos de emissão de poluentes do ar para os motores e veículos automotores novos; e) Documento 5 - Resoluçáo no 1, de 11 de fevereiro de 1993 - Complementada pela Resolução CONAMA n 242/98 para veículos com características especiais para uso fora de estradas; f) Documento 6 - Resoluçáo no 274, de 29 de novembro de 2000. Correlaçóes: Revoga os artigos 26 a 34 da Resolução CONAMA no 20/86; g) Documento 7 - BRASIL. Constituição Federal do Brasil, de 05 de outubro de 1988. A leitura dos documentos foi de suma importância para sedimentar o conhecimento referente à legislação pertinente ao tema.

A segunda etapa se deu mediante a realizaçáo de entrevistas com os participantes do esporte de aventura, com profissionais da comunidade local (engenheiros florestais, engenheiros químicos, biólogos, guardas parques, gestores ambientais), moradores locais e proprietários (que não moram no local). Para acessar os participantes usou-se o método bola-de-neve. Conforme Taylor e Bogdan (1996) apud Silva (1996) devem ser usados os seguintes indicativos: "enfoque direto", onde o pesquisador pede acesso, "alguém para indicar" e cartas de apoio de pessoas ou da instituição a qual pertence.

Ao estabelecer os primeiros diálogos para a pesquisa, o investigador deve descrever seus objetivos e como será realizada a pesquisa. Esta apresentação deve ser sincera, mas concisa, pois muitos detalhes podem complicar e dificultar o entendimento do que se quer. Quando se solicita acesso deve-se deixar bem claro que a privacidade e a ética não serão infringidas em nenhum momento. A negociaçáo com os praticantes e não praticantes se deu de forma direta e franca, mediante uma conversa e, em seguida, já foram aplicados os instrumentos de coleta das informaçóes, a fim de explorar se realmente a prática de motocross interfere no meio socioambiental do município.

$\mathrm{Na}$ segunda etapa também foram usados os registros em Diário de Campo, feitos pela pesquisadora in loco, a fim de anotar percepçôes e observaçóes. Para tal, foram realizadas visitas a campo para a coleta dos dados primários, sendo que os pontos foram colhidos com o Global Positioning System (GPS).

Conforme Molina Neto e Trivińos (1999), a prática de observação se constitui em um valioso instrumento na pesquisa qualitativa. O quesito principal da observação é tornar os registros os mais descritivos possíveis. A observação serve como um instrumento de coleta e informaçóes e requer que se utilizem processos cognitivos como: a atenção, a percepção, a memória e o pensamento, para observar os fatos e realidades sociais presentes. A observação deve ser contínua e sistemática com a função de registrar determinados fenômenos ou comportamentos. 
Segundo Taylor e Bogdan (1996) apud Silva (1996), as notas de campo proporcionam dados que são matéria-prima da observação, por isto devem ser o mais completo e amplo possível, descrevendo com detalhes o acontecido, para posterior análise. Para o registro das informaçóes observadas foram relatadas as impressóes em um Diário de Campo, com intuito de otimizar as informaçóes coletadas. De forma geral, no diário de campo constava a data, o local, horário, entrevistado, alguns relatos e as facilidades e desafios expressos para realização da coleta de dados.

Também faz parte do corpus de pesquisa os levantamentos de dados estatísticos, mediante questionário estruturado aplicado aos participantes da pesquisa. $\mathrm{O}$ questionário continha 07 (sete) perguntas fechadas e 03 (três) perguntas abertas.

A análise do conjunto do fluxo de dados: referencial teórico, dados qualitativos das entrevistas e do Diário de Campo e dados estatísticos descritivos oriundos dos questionários, se dará mediante triangulação. Para melhor organizar as análises, os dados serão discutidos a partir de categorias. As categorias de análise foram nomeadas em virtude das ideiasfonte (conteúdos) emergentes do fluxo de dados vistos no todo.

Para a análise, utilizou-se a "análise de conteúdo" que é um conjunto de técnicas de análise das comunicaçôes, que utiliza procedimentos sistemáticos e objetivos de descrição do conteúdo das mensagens (BARDIN, 1977). A técnica de análise de conteúdo refere-se ao estudo tanto dos conteúdos nas figuras de linguagem, reticências, entrelinhas, quanto dos manifestos.

\section{O PERFIL E A PERCEPÇÃO DOS ENTREVISTADOS}

\subsection{Perfil}

Foram realizadas 17 (dezessete) entrevistas, cujas profissóes eram as mais variadas: Funcionário Público Estadual 2 (dois); Funcionário Público Municipal 5 (cinco), Engenheiro Agrônomo 2 (dois), Engenheiro Florestal 2 (dois), Técnico Ambiental 1 (um), Comerciante 3 (três) e Produtor Rural 2 (dois). Destes 3 (três) são moradores onde as trilhas são realizadas (proprietários e vizinhos), 6 (seis) são motociclistas/ motoqueiros/trilheiros e 8 (oito) são população local (guarda-parques, comerciantes, entre outros). Destes $82 \%$ eram homens e $18 \%$, mulheres.

\subsection{Escolaridade}

Em relação à escolaridade dos entrevistados: 1 (um) Mestrado, 7 (sete) Superior Completo, 4 (quatro) Superior Incompleto, 5 (cinco) Ensino Médio Completo. No quesito escolaridade se percebe que todos os participantes possuem no mínimo o ensino médio completo, o que demonstra terem certo grau de compreensão em relação aos impactos que podem ser provocados pela prática de motocross.

\subsection{Ocupaçáo Profissional}

Os entrevistados têm as mais variadas ocupaçóes profissionais, entre elas: Funcionário Público, Supervisor Florestal, Recepcionista, Técnico Ambiental, Produtor Rural, Diretor Técnico e Consultor Industrial, Veterinário, Assessor, Vendedor, Analista de Georreferenciamento, Estagiário, Gerente comercial e Guarda Parque. Porém, dentre os que são os motociclistas/motoqueiros/trilheiros, $40 \%$ são comerciantes do próprio município.

\subsection{Meio Ambiente}

Em relação às perguntas abertas que constavam no questionário, uma delas se referia a "O que você entende por meio ambiente?". A maioria dos entrevistados 13 (treze), 76\% responderam: "São condiçôes naturais que influenciam na vida dos seres vivos, abrigando-os e regendo suas vidas, em todas as suas formas", o que demonstra certo entendimento sobre as questôes ambientais.

Conforme o Artigo $3^{\circ}$ da Lei 6938/81, Meio Ambiente é o conjunto de condiçôes, leis, influências e interaçôes de ordem física, química e biológica, que permite, abriga e rege a vida em todas as suas formas. Em segundo lugar com 18\% a resposta "habitat natural de um ser vivo", e com $6 \%$ um "conjunto de unidades ecológicas".

Era perguntado ainda se os entrevistados haviam percebido alguma mudança no meio ambiente após o início da realização das trilhas. Para este questionamento pode-se observar novamente que existem visôes distintas entre os entrevistados, onde um grupo com $53 \%$ entende que não há mudanças no meio ambiente e outro grupo com $47 \%$ diz que sim, que houve mudanças no meio ambiente.

\subsection{Impacto Socioambiental}

Em relação à noção de "impacto socioambiental", $82 \%$ das respostas afirmou que são "alteraçôes do meio ambiente seja ele físico, ecológico ou 
social", enquanto que $12 \%$ afirmaram ser a "destruição das matas e dos animais" e apenas 1 (um) entrevistado (6\%) entende que é a "poluição atmosférica terrestre". Quando perguntados se a prática de motocross trazia algum impacto ao meio ambiente, $59 \%$ respondeu que sim e $41 \%$ disse que não provocavam impactos.

\subsection{Trilhas e Motocross}

Por ocasião do questionamento sobre a prática de motocross no município de São Francisco de Paula, $65 \%$ dos entrevistados se mostraram favoráveis a ela (11 entrevistados), enquanto que 35\% manifestaramse contrários à prática ( 6 entrevistados). Cabe salientar que entre os contrários às trilhas estão os próprios moradores dos locais, que por vezes tem suas propriedades invadidas pelos "trilheiros", também dentro deste posicionamento estáo os guarda-parques, responsáveis por fiscalizar as unidades de conservação.

Quando os entrevistados eram perguntados se a prática de motocross traria algum impacto ao ambiente, houve uma divisão em três grupos distintos. Um grupo ( $41 \%$ dos entrevistados) entende haver baixo impacto ambiental, por estarem em harmonia com o meio ambiente; outro grupo (30\% dos entrevistados) respondeu que tal prática causa prejuízos ao meio ambiente; e, um terceiro grupo ( $29 \%$ dos entrevistados), disse não entender a pergunta ou não soube responder ao questionamento.

\section{IMPACTOS SOCIOAMBIENTAIS PROVOCADOS PELA PRÁTICA DE MOTOCROSS EM SÃO FRANCISCO DE PAULA}

\subsection{Emissáo de Gases e Ruídos}

O regulamento da Confederação Brasileira de Motociclismo (2006) informa no item 7.3 "vistoria da moto" que "a moto deve estar em bom estado mecânico, e sistema de escape com ruído dentro dos limites legais". Estes limites legais informados pela entidade estão (ou pelo menos deveriam estar) de acordo com o Código Brasileiro de Trânsito.

Geralmente, nos locais em que são realizadas as trilhas de motocross, a alteração da qualidade do ar é causada pela geraçáo de poeiras e materiais particulados que saem dos escapamentos das motos. Ao analisar esta alteração da qualidade do ar provocado pelas motos nos dias de trilhas (ou de competições) no município de São Francisco de Paula, foi medido o nível de $\mathrm{CO}$ (monóxido de carbono) liberado pelas motos na trilha.

Por meio do detector multigás (que mede $\mathrm{CO}$, O2) tem-se um valor inicial (antes da ocorrência das trilhas) e um valor após a passagem das motos. $\mathrm{Na}$ ocasião da mediçấo, na localidade de Boa Vista, distante cerca de $10 \mathrm{~km}$ (quilômetros) da sede do município, o valor inicial foi ZERO (antes da trilha) e após a passagem das motos (aproximadamente 480 motos), o valor quadriplicou. $\mathrm{O}$ detector multigás faz um alerta quando alcança os 34 ppm (parte por milhão), nesta ocasião, após a passagem das motos, o valor alcançou $114 \mathrm{ppm}$. O limite para exposição de trabalhadores conforme Lei 6.514/77 nº 15 , é de 34 ppm para 44 horas semanais.

No dia após a ocorrência desta trilha foi feito outro teste com o detector multigás, sendo constatado que as folhas das plantas do local ainda estavam cheias de $\mathrm{CO}$. Concentrações altas de $\mathrm{CO}$ no ar são potencialmente mortais, tanto para plantas e animais quanto para alguns micro-organismos.

Para emissão de gases, de acordo com a Resolução CONAMA nº. 342/03, que estabelece limites para emissão de gases contaminantes para os ciclomotores e motocicletas, os veículos com motores iguais ou maiores de $150 \mathrm{cc}$ (cilindradas) náo deverá exceder os seguintes valores: Monóxido de carbono: 2,0 g/ $\mathrm{km}$; Hidrocarbonetos: $0,3 \mathrm{~g} / \mathrm{km}$; Óxidos de nitrogênio: $0,15 \mathrm{~g} / \mathrm{km}$. (CONSELHO NACIONAL DO MEIO AMBIENTE, 2003)

Durante esta trilha também foi medido o ruído gerado pelas motos. Foi utilizado o "Decibelímetro", que mede a geração de ruídos. A máxima exposição diária permissível para uma pessoa é de 115 decibéis por 7 minutos, durante a trilha obteve-se valores entre 120 e 180 decibéis, geralmente as trilhas tem duração de 8 (oito) a 10 (dez) horas. Em função da geração de ruído constatou-se que houve afugentamento dos animais do entorno, principalmente dos pássaros.

\subsection{Compactaçáo do Solo e Geraçáo de Resíduos}

A compactaçáo do solo e a abertura de ravinas causadas pelas motos são consideradas impactos intensos no ambiente. Nos dias de trilha costuma-se ainda realizar a "limpeza da trilha", como denominada pelos "trilheiros", que seria a abertura da mata fechada para a passagem das motos. Os impactos nos ambientes naturais pela abertura de trilhas ou desmatamentos de uma determinada área provocam alteraçôes na dinâmica de todo um ecossistema, 
dentre estas alteraçôes a fauna é um dos principais alvos do impacto.

A compactação do solo, segundo Hamada (2004), resulta na redução da permeabilidade, portanto, se houver compactação do solo, a absorção de resíduos líquidos é muito dificultada. Nas trilhas, um dos impactos constatados é o vazamento de combustíveis (óleo, gasolina) das motos, que geralmente ficam expostos no solo ou na vegetação do entorno.

Em relação às trilhas deveria ser definido os limites de desmatamento e/ou remoção da cobertura vegetal (FOGLIATTI, 2004) para certos esportes de aventura, enquadrando-se aí o motocross. Fogliatti (2004) comenta que a construçáo de aterros para instalaçáo de infraestrutura, podem ocasionar distribuição, compactação e acabamento do solo. Como consequência disso, tem-se a alteração da drenagem natural, a influência na qualidade das águas, a aceleração dos processos erosivos, o aumento da poluição sonora e atmosférica e a perda de espécies vegetais e animais.

Com relação à drenagem, a interferência no fluxo natural das águas (FOGLIATTI, 2004) é um dos principais impactos das aberturas de trilhas. A abertura de trilhas, acessos, cortes e aterros ou desmatamentos criam obstáculos e interrupção ao escoamento espontâneo das águas ${ }^{3}$.

\subsection{Afugentamento de Animais}

O Instituto Brasileiro do Meio Ambiente e dos Recursos Naturais Renováveis (IBAMA), na portaria no 1.522 , de 19 de dezembro de 1989, apresenta a lista de animais ameaçados de extinção. Já a Constituição Federal, no artigo 225, $\$ 1^{\circ}$, inciso VII, concede ao poder público, a proteção da fauna e flora, evitando o risco em sua função ecológica (BRASIL, 1988), por isso, alguns municípios têm lei específica sobre o tema.

A abertura da mata fechada ou o desmatamento realizado pelos "trilheiros" provoca alto impacto na fauna. Alguns estudos sobre a ecologia das espécies destes locais demonstram alteraçôes na dieta e nos habitats dos animais, em decorrência das mudanças a que são expostos quando realizados estes esportes de aventura. Algumas espécies vegetais essenciais à alimentação destes animais são eliminadas com estas alteraçôes no ambiente, também foram constatadas

\footnotetext{
3 Os padrões ambientais brasileiros estão definidos na Lei n. 6938/81 (BRASIL, 1981), que dispóe sobre a Política Nacional do Meio Ambiente, para a qualidade do ar e das águas.
}

mudanças comportamentais na fauna e aumento dos índices de mortalidade (ANDRADE, 2007).

Com a passagem das motos, outro impacto constatado que ocorre em relação à fauna são os atropelamentos de animais silvestres causando ferimentos ou a morte destes, destruição dos ninhos das aves, entre estes animais estão os de pequeno porte como zorrilhos, tatus, cobras, aranhas, lagartos, quero-quero entre outros.

\subsection{Invasáo de Propriedades Particulares e Unidades de Conservaçáo}

A partir dos dados coletados nas entrevistas, pode-se chegar a um dos trajetos mais utilizados pelos "trilheiros" de/em São Francisco de Paula (Figura 1). Vale salientar que este trajeto passa por áreas particulares como fazendas, sítios, parque de exposiçóes e por áreas de APPs, inclusive passando pela zona urbana do município.

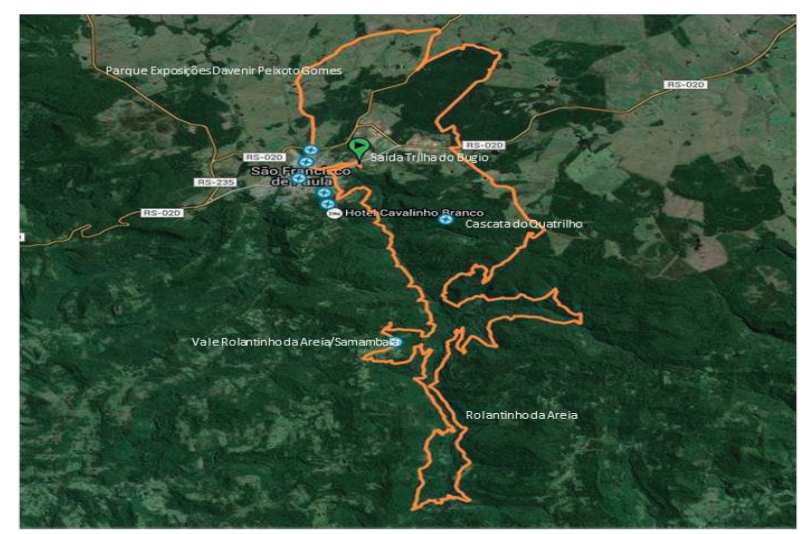

Figura 1 - Trajeto mais frequente das trilhas de motocross no município de Sáo Francisco de Paula/RS

Quando os esportistas do motocross entram nestas áreas é possível notar impactos significativos em relação ao solo, recursos hídricos, fauna, flora, ruídos e poeira. Após a passagem das motos é visível a alteraçáo provocada no ambiente como a exposiçấo de lixos e resquícios de fogueira em áreas próximas a cachoeiras ou cursos d'água. Quando os participantes do motocross fazem fogueiras em áreas de conservação estão afetando diretamente à fauna e a flora daquele local, além disso, existe a possibilidade de provocarem incêndios de altas proporçôes, o que seria ainda mais desastroso.

Estas invasóes têm provocado conflitos entre os apreciadores do motocross, a população local e os órgãos públicos de fiscalização ambiental, neste caso, a Secretaria Municipal de Proteção Ambiental. Segundo um dos guarda-parques entrevistado foram inú- 
meras as denúncias de moradores em relação às invasões às propriedades particulares e às UCs.

Os moradores locais entrevistados nesta pesquisa viram como principal problema na realização do motocross no município, a entrada sem permissão nas propriedades particulares. Comentam ainda que já ocorrerão casos onde os cadeados das porteiras de acesso às propriedades foram abertos. Outro ponto comentado por eles é que foram furtados materiais e equipamentos das propriedades enquanto ocorriam as trilhas.

Muitas vezes os percursos das trilhas são planejados passando por propriedades cujos consentimentos não foram dados, onde os proprietários não são informados. Houve casos, onde os motociclistas/motoqueiros entraram em pequenas plantaçôes e cortaram as cercas das propriedades. Do outro lado estáo os proprietários destes locais, que não sabem o que fazer em relação ao ocorrido. Alguns destes optaram em denunciar aos órgãos públicos (Ministério Público Estadual, Brigada Militar, Prefeitura Municipal).

Em São Francisco de Paula, as trilhas costumam acontecer também em áreas pertencentes às Unidades de Conservação (UCs). Diante desta situação, tornase preocupante o estado de conservaçáo das UCs, por serem áreas de grande riqueza natural, devem ter sua cobertura vegetal obrigatoriamente mantida, e que estão à mercê destas ocorrências.

Conforme o Plano Ambiental Municipal (2008), o município de São Francisco de Paula tem 7 (sete) UCs entre parques, florestas e estaçóes ecológicas, sendo um número grande de áreas com poucos funcionários para fazerem a fiscalização. Outro ponto a ser ressaltado é que geralmente as trilhas ocorrem aos finais de semana, quando os órgãos fiscalizadores trabalham em regime de "plantão", ou seja, atendem apenas denúncias e/ou ocorrências emergenciais.

\section{CONSIDERAÇÓES FINAIS}

Com a realização deste trabalho pode-se observar que a prática de enduros, rallys ou trilhas de motocross que não levam em consideração normas ambientais tendem a gerar efeitos negativos ao ambiente. Os principais impactos socioambientais encontrados a partir deste trabalho foram a poluição de gases emitidos pelos escapamentos das motocicletas, a geração de resíduos, ruídos além do permitido, compactação do solo, abertura de sulcos que com as águas das chuvas podem ser aumentado e também os conflitos so- ciais que o esporte tem provocado entre moradores locais e praticantes.

Tais impactos socioambientais variam de acordo com o espaço em que é praticado o motocross, com o tempo de duração do enduro (competição) e o período em que é realizado (condiçốes climáticas). Embora se tenha constatado mais efeitos negativos em relação à prática do motocross, percebeu-se também que um dos impactos positivos e que foi comentado por alguns entrevistados, seria em relaçáo ao aumento de público no comércio. Pois com a realização de rallys, enduros e/ou trilhas, seria atraído um público assíduo (praticantes destes esportes) ao município, o que tenderia a gerar impostos e renda à população local. No entanto, caberia um estudo mais aprofundado sobre esta economia e se, realmente, traria/seria um impacto positivo aos cofres municipais.

Verifica-se que o poder público local deve se manifestar buscando soluções para negociar os conflitos e, portanto, fica evidente que a prática de motocross no município deve ser regrada, criando-se normativas que rejam a atividade, levando em consideraçáo apontamentos e características físicas do ambiente, assim como também, levar à cabo a participação efetiva da comunidade e, obviamente, com os próprios praticantes do esporte. Assim, se faz necessário a realização de levantamentos e acompanhamentos, que permitam maior conhecimento sobre os impactos socioambientais gerados pela prática do motocross.

No entanto, náo são somente as leis que tem a funçâo de "educar", pois os praticantes do esporte também devem se conscientizar da relação que o esporte tem com o ambiente, de que um não vive sem o outro - homem e natureza interagem e necessitam um do outro e, portanto, preservar a natureza é essencial para que se tenha um meio ambiente saudável.

Sendo assim, observa-se que essa consciência deve partir dos agentes que estimulam a prática dessas atividades, é de suma importância que os praticantes ou não, sejam orientados por pessoas qualificadas antes de praticar algumas das atividades, portanto, o planejamento torna-se fundamental. Um evento esportivo de trilha de motocross gerenciado através de práticas socioambientais que respeitam o meio ambiente e as populaçóes locais, geram resultados econômicos satisfatórios aos envolvidos direta ou indiretamente no evento, como as comunidades, os participantes, os organizadores, os representantes públicos e os patrocinadores.

Logo, conclui-se que a relação entre esporte, 
meio ambiente e a sociedade é uma relação de mão dupla, visto que em alguns momentos o esporte pode exercer uma influência positiva sobre o meio ambiente, desde que seja praticado de forma racional, respeitando a natureza, já em outros momentos podem ocasionar alteraçóes no mesmo ou até degradá-lo.

O que se propóe aqui é que exista uma significativa preocupação da comunidade local, do poder público e dos praticantes do esporte por um processo de sensibilizaçáo ambiental consciente de vivência do lazer em áreas naturais. Nosso conhecimento sobre o planeta é pequeno, mas suficiente para saber que precisamos aprender a habitá-lo e usufruir dele de maneira consciente e responsável, sem esquecer-se de preservá-lo para que possa sustentar também as geraçóes futuras.

\section{REFERÊNCIAS}

AMORIM, S.; NAVARRO, P.; BITENCOURT, V. R. Off Road. In: DACOSTA, Lamartine. Atlas do Esporte no Brasil: atlas do esporte, educação física e atividades físicas de saúde e lazer no Brasil. Rio de Janeiro: Shape, 2005. p. 422-423.

ANDRADE, W. J. Manejo de trilhas para o Ecoturismo. In: MENDONÇA, R.; NEIMAN, Z. (Org.). Ecoturismo no Brasil. Barueri: Manole, 2005. p.131-152.

BACCHIEGGA, F. Desvendando o campo da Sociologia Ambiental: revisão de artigos selecionados. In: ENCONTRO NACIONAL DA ANPPAS, 5., Belém, Pará, 2012. [Anais...]. Belém: [S.n.], 2012. Disponível em: <http: // www.anppas.org.br /encontro6 /anais / ARQUIVOS /GT10 -1057-934-20120619201804.pdf >. Acesso em: 30 maio 2016.

BALSAN, R. Impactos Decorrentes da Modernizaçấo da Agricultura Brasileira. Campo-Território: Revista de Geografia Agrária, Francisco Beltrão, v. 1, n. 2, p. 123-151, 2006.

BARDIN, L. Análise de Conteúdo. Lisboa: Ediçôes 70, 1977.

BRASIL. Constituição de 1988. Constituição Federal do Brasil de 05 de outubro de 1988. Diário Oficial [da] República Federativa do Brasil. Poder Executivo, Brasília, 05. out. 1988.

Lei 6.938, de 31 de agosto de 1981. Política Nacional do Meio Ambiente, seus fins e mecanismos de formulaçấo e aplicação, e dá outras providências. Disponível em: < http://www.planalto.gov.br/ccivil 03/ leis/L6938.htm>. Acesso em: 20 jul. 2016.
CONSELHO NACIONAL DO MEIO AMBIENTE. Resoluçáo no 357, de 17 de março de 2005. Dispóe sobre a classificaçấo dos corpos de água e diretrizes ambientais para o seu enquadramento, bem como estabelece as condiçốes e padróes de lançamento de efluentes, e dá outras providências. Brasília, DF: CONAMA, 2005.

. Resoluçáo no 5, de 15 de junho de 1989. Dispóe sobre o Programa Nacional de Controle da Poluiçáo do Ar - PRONAR.. Brasília, DF: CONAMA, 2005.

. Resoluçáo no 1, de 23 de janeiro de 1986. Dispôe sobre Impacto Ambiental. Brasília, DF: CONAMA, 2008.

. Resoluçáo no 18, de 6 de maio de 1986. Brasília, DF: CONAMA, 2008.

. Resoluçáo no 1, de 11 de fevereiro de 1993. Estabelece, para veículos automotores nacionais e importados, exceto motocicletas, motonetas, triciclos, ciclomotores, bicicletas com motor auxiliar e veículos assemelhados, nacionais e importados, limites máximos de ruído com o veículo em aceleração e na condição parado. Brasília, DF: CONAMA, 2008.

Resoluçáo no 274 , de 29 de novembro de 2000. Brasília/DF: CONAMA, 2008.

CONFEDERAÇÃO BRASILEIRA DE AUTOMOBILISMO. Regulamentos 2006: Rally e Off-Road. Rio de Janeiro, 2006.

COSTA, S. M. Contribuiçáo Metodológica ao Estudo da Capacidade de Carga Turística em Áreas Preservadas: o caso da Unidade de Conservaçáo do Gericinó-Mendanha (RJ). 2004. 124 f. Dissertaçáo (Mestrado em Geografia) Programa de Pós Graduaçâo em Geografia, Universidade Federal do Rio de Janeiro, Rio de Janeiro, 2004.

FERNANDES, E. Impacto socioambiental em áreas urbanas sob a perspectiva jurídica. In: MENDONÇA, F. (Org.). Impactos socioambientais urbanos. Curitiba: UFPR, 2004.

FERREIRA, P. F. M. Diagnóstico dos impactos socioambientais urbanos em Itacaré (BA). 2011. 158 f. Dissertação (Mestrado) - Instituto de Geociências, Universidade Estadual de Campinas, Campinas, 2011.

FOGLIATTI, M. C. Avaliaçáo dos impactos ambientais: aplicação aos sistemas de transporte. Rio de Janeiro: Interciência, 2004.

GIL, A. C. Métodos e técnicas de pesquisa social. São Paulo: Atlas, 2008.

HAMADA, J. Influência da compactação de um solo are- 
noso na infiltração e retenção da carga orgânica de chorume. Engenharia Sanitária e Ambiental, Rio de Janeiro. v.9, n.3, jul./set., 2004, p. 180-186.

\section{INSTITUTO BRASILEIRO DO MEIO AMBIENTE E} DOS RECURSOS NATURAIS RENOVÁVEIS. Portaria $n^{\circ} 1.522$, de 19 de dezembro de 1989. Reconhece a Lista Oficial de Espécies da Fauna Brasileira Ameaçada de Extinção. Disponível em: <http://www.ibama.gov.br/licenciamento/modulos/arquivo.php?cod_arqweb=port1522>. Acesso em: 30 mai. 2016.

MENDONÇA, F. Aspectos da problemática ambiental urbana da cidade de Curitiba - PR e o mito da "capital ecológica”. Espaço e Tempo, São Paulo, n. 12, 2002.

MOLINA NETO, V.; TRIVIÑOS, A. N. S. A pesquisa qualitativa na educaçáo física. Porto Alegre: Sulina, 1999.

MARQUES, F. C. Velhos conhecimentos, novos desenvolvimentos: transiçôes no regime sociotécnico da agricultura: a produção de novidades entre agricultores produtores de plantas medicinais no Sul do Brasil. 2009. $220 \mathrm{f}$. Tese (Doutorado em Desenvolvimento Rural) - Programa de Pós-Graduação em Desenvolvimento Rural, Faculdade de Ciências Econômicas, Universidade Federal do Rio Grande do Sul, Porto Alegre, 2009.

MORAES, L. C. A. Ponderação de Impactos Socioambientais dos Encontros de

Motocicletas: uma proposta metodológica: o caso de Penedo, RJ. Revista Caribeña de Ciencias Sociales, 2014. Disponível em: < http://xn--caribea-9za.eumed.net/ wp-content/uploads/motocicletas.pdf >. Acesso em: 29 Jun. 2016.

PAIXÃO, R.C; NAZARI, J. Motocross: emoção com responsabilidade. 2010. Disponível em: < http://www.efdeportes.com/efd149/motocross-emocao-com-responsabilidade.htm>. Acesso em: 29 jun. 2016.

PHILIPPI JUNIOR, A.; MAGLIO, I. C. Política e Gestão Ambiental: Conceitos e Instrumentos. In: PHILIPPI JUNIOR., A.; PELICIONE, C. F. (Org.). Educação ambiental e sustentabilidade. Barueri: Manole, 2005. p. 217-256.

PRADO, L. R. Curso de direito penal brasileiro: parte geral. 12. ed. rev., atual. e ampl. São Paulo: Revista dos Tribunais, 2013. v. 1.

SALVATI, S. S. Certificação em Ecoturismo: liçôes mundiais e recomendações para o Brasil. Brasília: WWF Brasil, 2001.
SANTANA, R. B. O Impacto ambiental dos esportes de aventura. 2011. Disponível em: < http://amapac.blogspot.com.br/2011/05/o-impacto-ambiental-dos-esportesde.html >. Acesso em: 23 maio 2016.

SÃO FRANCISCO DE PAULA. Plano Ambiental Municipal. Prefeitura de São Francisco de Paula -Secretaria Municipal de Saúde e Meio Ambiente - Coordenação do Meio Ambiente. 2008.

TORRES, N. Avaliaçáo de websites e indicadores de egov em municípios brasileiros: relatório final. São Paulo: TeciGov-FGV-SP, 2006. Disponível em: <http://www. sumaq.org/egov/img/publicaciones/5.pdf>. Acesso em: 3 maio 2016.

ZANONI, M. A questão ambiental e o rural contemporâneo. Desenvolvimento e Meio Ambiente, n. 10, p. 101110, jul./dez. 2004. Curitiba: UFPR, 2004. 